\title{
A MOBILE SYSTEM COMBINING LIDAR AND SUNPHOTOMETER ON- ROAD MEASUREMENTS: DESCRIPTION AND FIRST RESULTS
}

\author{
Ioana Popovici, ${ }^{1,2 *}$, Philippe Goloub ${ }^{1}$, Thierry Podvin ${ }^{1}$, Luc Blarel ${ }^{1}$, Rodrigue Loisil ${ }^{1}$, Augustin \\ Mortier $^{3}$, Christine Deroo ${ }^{1}$, Fabrice Ducos ${ }^{1}$, Stéphane Victori $^{2}$, Benjamin Torres ${ }^{4}$ \\ ${ }^{1}$ Univ. Lille, CNRS, UMR 8518 - LOA - Laboratoire d'Optique Atmosphérique, F-59000 Lille, France \\ *ie.popovici@ed.univ-lille1.fr \\ ${ }^{2}$ Cimel Electronique, 75011 Paris, France \\ ${ }^{3}$ Norwegian Meteorological Institute, 0313 Oslo, Norway \\ ${ }^{4}$ GRASP-SAS, 59000 Lille, France
}

\begin{abstract}
The mobile system described in this paper integrates a commercial eye-safe lidar (CIMEL), a sunphotometer and in situ instruments. The system is distinguished by other transportable platforms through its capabilities to perform onroad measurements. The potential of a commercial lidar to provide reliable information on aerosol properties is investigated through comparison with a multi-wavelength Raman lidar. First results from observation campaigns in northern France are presented.
\end{abstract}

\section{INTRODUCTION}

Existing lidar networks consist of different systems with various configurations, from singlewavelength elastic lidars to multi-wavelength Raman lidars. Most systems are complex instruments that require regular maintenance and controlled environment for their operation, so they are predominantly installed in laboratory rooms. Therefore, their use for atmospheric profiling is limited over a fixed location. Nevertheless, aerosol distribution is highly variable in case of sudden events; e.g. pollution episodes, dust and fire outbreaks, volcano eruptions, long-range transports and dispersion of pollutants from emission sources. In these situations, field observations are important, as the spatial variability is impossible to assess from point measurements.

Mobile observations are one of the best solutions to map the extent of such events and to study the regional gradients. If lidars could be easily deployed at the time needed, the number of applications would rapidly increase, from the validation of satellite measurements and model predictions to the investigation of plumes at industrial sites.
Currently, the term mobile is referred to scanning lidars and transportable systems (lidar or in situ), used to perform measurements in remote places, during campaigns or simply outside laboratory rooms. Other works describe mobile laboratories performing lidar [1] and particle/gas [2] on-line measurements during vehicle's motion. Nonetheless, the capability of deploying lidars and other instruments for on-road measurements is not enough explored.

For the first time, the description of a compact mobile system to perform on-road measurements, which integrates a lidar, a sunphotometer and optical particle counters, is presented here. The uniqueness of the system lies mainly in the sunphotometer, capable to track the sun during vehicle's motion, and the synergy of joint lidar and sunphotometer measurements to derive extinction profiles along the investigated route.

In this paper, after the description of the mobile system's current configuration, we start a discussion on the overlap function used for correction and confirm the lidar quality by comparison to data from an EARLINET station. Finally, the application of the mobile system is illustrated by measurements in northern France.

\section{MOBILE SYSTEM DESCRIPTION}

Most mobile lidars deployed in field campaigns are bulky systems, requiring large vehicles for their installation and transportation. Compared to such systems, the mobile system described here is more compact and robust. The MAAMS (Mobile Automated Aerosol Monitoring System) is a light commercial vehicle (Renault Kangoo), equipped with a lidar, a sunphotometer and in situ instruments. An overview of the mobile system is given in Figure 1. The van's trunk was modified to allow the installation of instruments. Moreover, 
the vehicle was equipped with an electrical installation and an external outlet. To continuously operate all the instruments, a $12 \mathrm{~V} / 300 \mathrm{Ah}$ AGM battery and a power inverter were installed in the van.

\subsection{Instruments}

The lidar included in MAAMS payload is currently a CE370 Lidar, an aerosol backscattering lidar emitting at $532 \mathrm{~nm}$, developed and commercialized by Cimel Electronique (www.cimel.fr). The system uses a diode-pumped Nd:YAG laser with small laser pulse energy of $20 \mu \mathrm{J}$ and a high repetition rate of $4.7 \mathrm{kHz}$. The instrument's design consists of a shared transmitter-receiver telescope connected to the control and acquisition unit through a $10 \mathrm{~m}$ optical fiber. The telescope has a diameter of 200 $\mathrm{mm}$ and narrow field of view (55 $\mu \mathrm{rad})$ to limit the background light. Backscattered light is detected by an avalanche photodiode detector (APD), running in photon-counting mode. The lidar sounds the atmosphere up to $15 \mathrm{~km}$ with a vertical resolution of $15 \mathrm{~m}$. It is autonomous, lightweight and compact and operates in eye-safe mode, requiring no authorization for its operation. These features make it suitable for a mobile system.

The lidar control and acquisition unit, enclosing the optical and electronic components, is installed on vibration isolators to protect the optical alignment from shock while the vehicle is moving. Likewise, the lidar transmitter-receiver telescope is fixed to the van using a specially designed support mounted in the van's floor, in order to ensure stability during movement. Furthermore, the shared telescope design eliminates any optical alignment problems.

The sun-tracking photometer PLASMA [3] (Photomètre Léger Aéroporté pour la Surveillance des Masses d'Air), developed by LOA, is used to derive spectral aerosol optical depths (AOD) over the 0.343-1.23 $\mu \mathrm{m}$ range. PLASMA can move in elevation $\left(0-90^{\circ}\right)$ and azimuth $\left(0-360^{\circ}\right)$ and can rotate in azimuth thanks to a ring power connector, which makes it suitable for mobile applications.

The $O P C-N 2$ is an optical particle counter designed by Alphasense (www.alphasense.com).
It measures particle size distribution from 0.38 to $17 \mu \mathrm{m}$ within 16 channels every 6 seconds with a flow rate of $1.2 \mathrm{~L} / \mathrm{min}$.

Another particle counter, mini-WRAS, developed by GRIMM, has been also mounted in MAAMS. The instrument measures the particle size distribution in 40 channels, from $10 \mathrm{~nm}$ to $25 \mu \mathrm{m}$ every minute with a flow rate of $1.2 \mathrm{~L} / \mathrm{min}$.

A meteorological probe mounted on the van is used to measure the temperature, the relative humidity and the atmospheric pressure. Finally, MAAMS is equipped with a GPS navigation system, to map the mobile measurements and a camera, used to record sky cloudiness.

Data is transferred to LOA database using a $3 \mathrm{G}$ communication and is processed routinely.

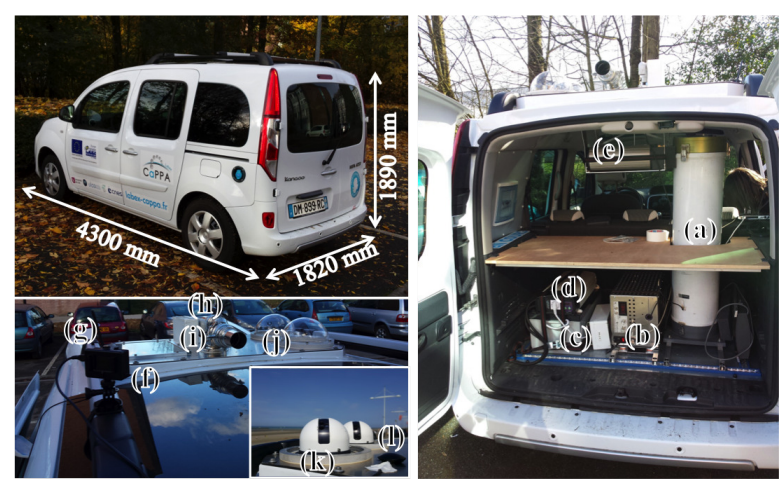

Figure 1. Photographs of the mobile system and the components mounted inside and outside the vehicle: (a) Lidar transmitter-receiver optical head, (b) Lidar control and acquisition unit, (c) battery, (d) power inverter, (e) optical particle counter, (f) action camera, (g) $3 G$ antenna, (h) meteorological probe, (i) housing for PLASMA's compass, (j) protection domes for PLASMA, (k) PLASMA sunphotometers, (l) GPS

\subsection{Overlap function}

Figure 2 shows the overlap correction used for CE370 lidar (red curve). It is assessed using slope method from fixed vertical observations (black curve), when fair weather or homogeneous atmosphere conditions are met. A correction is possible between $150 \mathrm{~m}$ and $5 \mathrm{~km}$, where complete overlap is reached. In order to verify the correction, we compared it with the ratio of LILAS (Multiwavelength-Raman lidar) and CE370 (mobile lidar) signals (green curve), which is a good estimate of the overlap function. A mean difference of $4 \%$ between the two overlap 
functions (green and black curves) is obtained for the $0.15-5 \mathrm{~km}$ range. LILAS, part of EARLINET, successfully went through its quality assurance chain (Rayleigh fit, telecover test, [4]) and is therefore considered as a reference in this comparison exercice. Preliminary results show a good agreement, which confirms the reliability of the function used for overlap correction and the quality of our data.

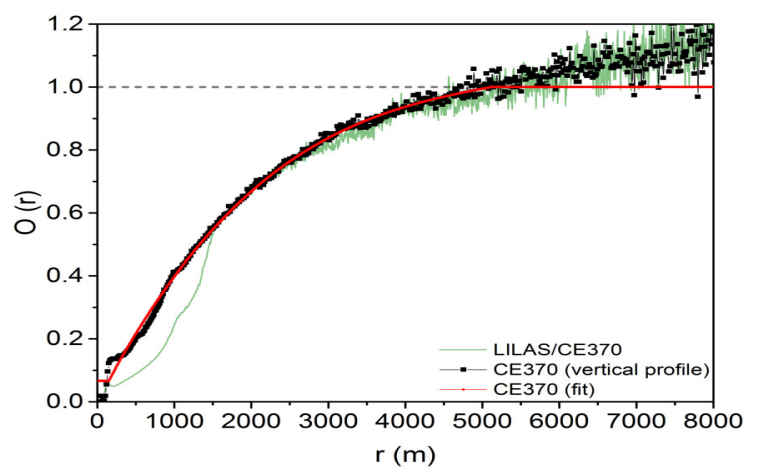

Figure 2. Overlap function of CE370 lidar (red) and ratio of Raman (LILAS) and CE370 micro-lidar signals (green).

\section{RESULTS}

Mobile measurements have been performed in northern France during spring and summer 2015 and 2016, as higher aerosol loadings are generally observed throughout these periods. In this section, we focus our analysis on the day of August $26^{\text {th }}$, 2016 , since it is representative for strong spatial variability within the region.

The mobile system was driven from Lille (LL) to Dunkerque (DK), situated at $80 \mathrm{~km} \mathrm{NW}$ from Lille. Figure 3 shows the lidar Range-Corrected Signals (RCS) recorded along the investigated route. Higher aerosol concentration is observed for Lille up to $1 \mathrm{~km}$, which decreases towards the coastal region (DK). Moreover, outside Lille region, the presence of several aerosol layers up to $5 \mathrm{~km}$ is revealed. These layers are hardly observed in Lille due to the strong backscatter in the lower altitudes

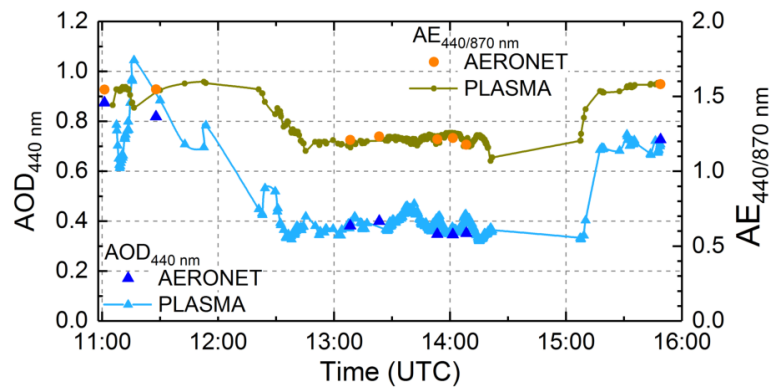

Figure 4. AOD (440 nm) and Extinction Angström Exponent (AE) values measured by PLASMA on the round-trip between Lille and Dunkerque Values from AERONET stations are also reported as reference.

The Figure 4 shows Aerosol Optical Depth (AOD) and Angstrom Exponent (AE) processed from PLASMA data using AERONET processing system. A strong variability can be seen between the two end points (LL and DK). High AOD values of $0.6-0.8$ were recorded at Lille and surroundings between 11:00 and 11:30 UTC and decreased rapidly to 0.37 when arriving at Dunkerque around 13:00 UTC. Moreover, AE values decreased from 1.4-1.6 at Lille to 1.2 at Dunkerque, indicating a change in columnar microphysical properties along the road. During one hour of stationary measurements starting from 13:07 UTC, the AOD levels remained stable around 0.4. On the way back to Lille, AOD and AE values increased to 0.75 and 1.6 , respectively.
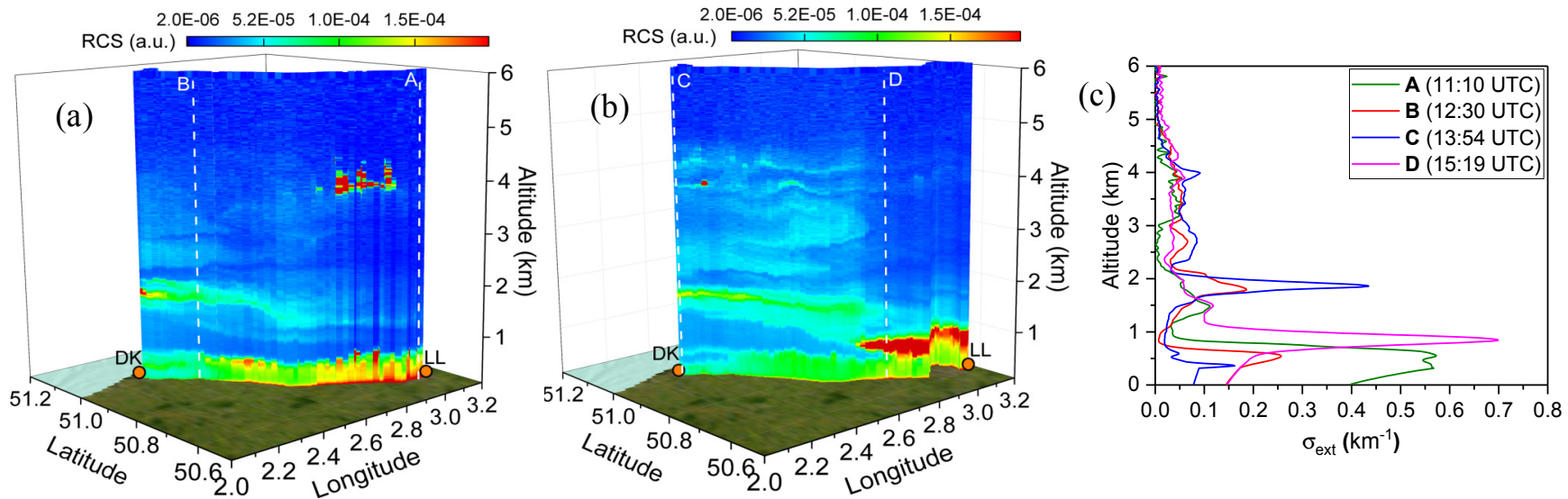

Figure 3. 3D color-coded spatial variability of lidar range-corrected signals along: (a) Lille (LL)-Dunkerque (DK), (b) Dunkerque (DK)-Lille (LL) transects. (c) Extinction coefficient profiles derived from lidar-sunphotometer measurements. The white dotted lines and letters $(A, B, C, D)$ indicate the location of the profiles chosen for analysis. 
A good consistency is observed between AOD and AE values from PLASMA and the closest AERONET stations, which demonstrate the reliability of PLASMA sunphotometer measurements. From the synergy of lidar and sunphotometer measurements, vertical extinction profiles (Figure $3 \mathrm{c}$ ) are derived using BASIC algorithm [5]. The profiles taken at different locations evidence the presence of several layers. The first one, up to $1 \mathrm{~km}$ at Lille is the boundary layer, whose height decreases to $0.6 \mathrm{~km}$ at DK (continental vs. coastal). A second layer is observed on $\mathrm{A}$ and $\mathrm{D}$ profiles at $1.5 \mathrm{~km}$, but with a slight shift in altitude on B and C $(1.8 \mathrm{~km})$. A third layer is seen between 2 and $5 \mathrm{~km}$. Backtrajectories and forecast dust models suggest that aerosols in this range are of Saharan origin. Several instruments along the coastal regions observed this dust intrusion. The upgrade of MAAMS with a $2 \lambda$ micro-lidar (CE376) will be helpful in the analysis of such complex cases. Figure 5 presents size distributions retrieved by GRASP-AOD [6] from PLASMA AOD measurements. Column-integrated size distribution can be obtained at different points on the investigated transect. At Lille and surroundings (A, D), both fine and coarse mode are present with nonetheless a higher fine mode fraction. For Dunkerque, fine and coarse modes have equal amplitudes. Results from retrievals are in good consistency with AERONET retrievals.

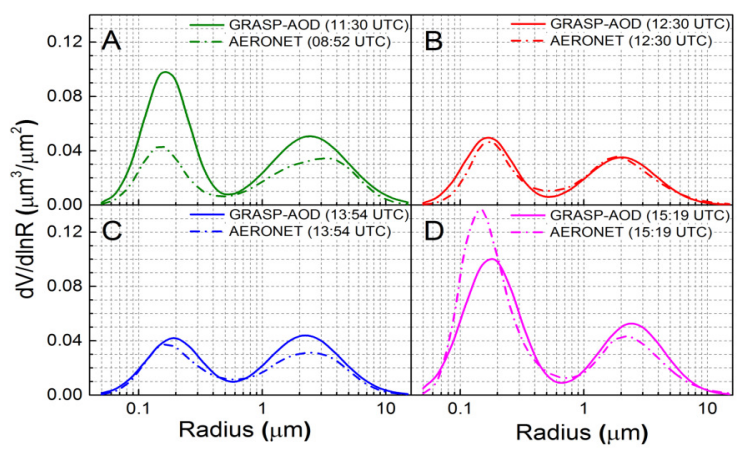

Figure 5. Size distributions retrieved by GRASP-AOD using AOD from PLASMA sun-photometer. The size distributions from the closest AERONET inversions are also represented as a reference.

\section{CONCLUSIONS}

The MAAMS mobile system configuration has been described, demonstrating its robustness for mobile applications. Preliminary comparisons against a Raman lidar and AERONET show good agreement between measurements and retrievals, respectively. Results for the analyzed example have shown variations of AOD betweeen 0.32 to 1.04 in $80 \mathrm{~km}$ range and 50 minutes time interval and highly variable aerosols vertical distribution. The presence of dust in the $2-5 \mathrm{~km}$ altitude range is indicated, which, added to an important event of local pollution, illustrate an interesting case of spatial and vertical variability.

\section{ACKNOWLEDGEMENTS}

The authors would like to thank to ANRT France and CIMEL Electronique for the financial support of the $\mathrm{PhD}$ work of Ioana Popovici. We also acknowledge the support from CaPPA project and SNO PHOTONS/AERONET from CNRS-INSU.

\section{References}

[1] Raut, J.-C., and Chazette, P., 2009: Assessment of vertically-resolved $\mathrm{PM}_{10}$ from mobile lidar observations, Atmos. Chem. Phys. 9, 8617-8638.

[2] Drewnick, F., Böttger, T., von der WeidenReinmüller, S.-L., Zorn, S.R., Klimach, T., Schneider, and J., Borrmann, S., 2012: Design of a mobile aerosol research laboratory and data processing tools for effective stationary and mobile field measurements, Atmos. Meas. Tech. 5, 1443-1457.

[3] Karol, Y., Tanré, D., Goloub, P., Vervaerde, C., Balois, J.Y., Blarel, L., Podvin, T., Mortier, A., and Chaikovsky, A., 2013: Airborne sun photometer PLASMA: concept, measurements, comparison of aerosol extinction vertical profile with lidar, Atmos. Meas. Tech. 6, 2383-2389.

[4] http://www.actris.net/Portals/97/Publications/ quality\%20standards/lidar/QA-

InternalCheckups_version_121017b.pdf, EARLINETInternal Checkups, V. Freudentalher

[5] Mortier, A., Goloub, P., Podvin, T., Deroo, C., Chaikovsky, A., Ajtai, N., Blarel, L., Tanré, D., and Derimian, Y., 2013: Detection and characterization of volcanic ash plumes over Lille during Eyjafjallajokull eruption, Atmos. Chem. Phys. 13, 3705-3720.

[6] Torres, B., Dubovik, O., Fuertes, D., Schuster, G., Cachorro, V.E., Lapionak, T., Goloub, P., Blarel, L., Baretto, A., Mallet, M., Toledano, C., and Tanré, D., 2016: Advanced characterization of aerosol properties from measurements of spectral optical depth using the GRASP algorithm, Atmos. Meas. Tech. Discuss, doi:10.5194/amt-2016-334, in review. 